\title{
High capacitance carbon-based xerogel film produced without critical drying
}

\author{
Yousheng Tao, ${ }^{1, a)}$ Morinobu Endo, ${ }^{1}$ Risa Ohsawa, ${ }^{2}$ Hirofumi Kanoh, ${ }^{2}$ and \\ Katsumi Kaneko ${ }^{2, b)}$ \\ ${ }^{1}$ Institute of Carbon Science and Technology, Shinshu University, Nagano 380-8553, Japan \\ ${ }^{2}$ Department of Chemistry, Graduate School of Science, Chiba University, Chiba 263-8522, Japan
}

(Received 8 May 2008; accepted 10 August 2008; published online 13 November 2008)

\begin{abstract}
We report the production of carbon-based xerogel film without the need for supercritical drying. Xerogel samples were characterized with field emission scanning electron microscopy, nitrogen adsorption/desorption at $77 \mathrm{~K}$, Raman spectroscopy, thermogravimetric analysis, and electrical conductivity and cyclic voltammetry measurements. Experimental results reveal that the film is largely crack free and homogeneous in thickness, and, importantly, has high surface area, large nanopore volume, and an excellent performance for electrical charge storage-both per unit mass and unit volume. These results indicate that the film has potential applications for electrical energy storage devices. (C) 2008 American Institute of Physics. [DOI: 10.1063/1.2976684]
\end{abstract}

Nanoporous carbon films have been of great interest for many years because of their potential use in separation and purification, catalysis, and chromatographic separation and for such applications as electric double-layer capacitors, biocatalytic sensors, and microscopes. ${ }^{1-7}$ Although numerous methods such as chemical vapor deposition, hydrothermal decomposition of carbide compounds, and polymer coating and pyrolysis have been developed for the fabrication of carbon film, ${ }^{8-10}$ easily scalable self-supported nanoporous carbon films have not yet been obtained with any of them. The following promising methods for fabricating the pore structure of carbon film have recently been reported: colloidal silica imprinting, microbead patterning, and presynthesized mesoporous silica scaffolding. ${ }^{11-14}$ However, these methods are tedious and prone to surfactant cost, incomplete infiltration of carbon precursors, formation of nonporous carbon on the external surface of the mesoporous powders, massive loss of carbon in the form of volatile carbon-containing species during pyrolysis, and difficulty in controlling the macroscopic morphology. ${ }^{15,16}$ Moreover, these methods are extremely difficult to apply to the fabrication of large-scale uniform nanoporous films. ${ }^{15}$ Although efforts have been made recently to synthesize nanoporous carbon by direct pathways of nanocasting ${ }^{17}$ and to prepare ordered porous carbon film through self-assembly of block copolymers, ${ }^{15}$ a scalable method for preparing nanoporous carbon films has not yet been established.

Since the pioneering demonstration of Kistler ${ }^{18}$ of the pore continuity of aerogels, much attention has been directed at the sol-gel process followed by supercritical drying for fabricating porous materials. ${ }^{18}$ Pekala and co-workers ${ }^{19,20}$ succeeded in preparing carbon aerogel, which is carbonized resorcinol-formaldehyde aerogel pyrolyzed in an inert atmosphere such as nitrogen. Due to their large surface area and easily tunable nanoporosities, such materials have received considerable attention in the study of the fundamentals of materials science and for commercial application to hydrogen fuel storage, catalysis, and chromatographic separation

\footnotetext{
a)Electronic mail: tao@endomoribu.shinshu-u.ac.jp.

${ }^{b)}$ Electronic mail: kaneko@ pchem2.s.chiba-u.ac.jp.
}

and for use in supercapacitors, gas diffusion electrodes in proton exchange membrane fuel cells, and anodes in rechargeable lithium ion batteries. ${ }^{21-23}$ Unfortunately, the supercritical drying required to prevent collapse of the highly nanoporous aerogel is expensive although supercritical processes can be used on a large commercial scale. In this letter we report a supercritical drying-free method for preparing uniformly thin carbon xerogel film (CXF). The prepared CXF exhibited excellent electrical charge storage.

The CXF was synthesized using the slit-space film model and resorcinol $\left[\mathrm{C}_{6} \mathrm{H}_{4}(\mathrm{OH})\right]_{2}$ (min. 99.0\%), formaldehyde solution ( $\mathrm{HCHO})(36.0 \%-38.0 \%)$, sodium carbonate $\left(\mathrm{Na}_{2} \mathrm{CO}_{3}\right)$ (min. 99.5\%), and ion-exchanged water as sources, of which the molar ratio was 1:2:0.025:0.4. All agents were used as received from Wako Pure Chemical Industries, Ltd. without further purification. The polycondensation and polymerization of resorcinol with formaldehyde was performed for 1 day at room temperature, afterward for 1 day at $323 \mathrm{~K}$, and successively for 3 days at $363 \mathrm{~K}$. After the reaction cell was opened, the resorcinol-formaldehyde polymer xerogel film was dried in air at $298 \mathrm{~K}$ and 101.3 $\times 10^{3} \mathrm{~Pa}$. The dried film was pyrolyzed at $1323 \mathrm{~K}$ in a nitrogen atmosphere. A shiny black and slightly flexible CXF was obtained. Field emission scanning electron micrographs (FE-SEMs) of the samples were obtained using a scanning electron microscope (JEOL, JSM-633F) operated at an accelerating voltage of $5.0 \mathrm{kV}$. The nitrogen adsorption/desorption isotherms were measured at $77 \mathrm{~K}$ using a gas adsorption analyzer (Quantachrome, Autosorb-1). The samples were evacuated at $10^{-4} \mathrm{~Pa}$ and $383 \mathrm{~K}$ for $2 \mathrm{~h}$ prior to the adsorption measurement. The Raman spectra were obtained with a laser Raman spectrometer (JASCO, NRS-1000) controlled by computer. Sample excitation was done with the $532 \mathrm{~nm}$ line of a Spectra-Physics LD laser. The scattered light was detected with a LN/CCD-576E GaAs photomultiplier tube. Thermogravimetric analysis (TGA) of the samples was performed using a thermal analyzer (Seiko Instruments, TG/ DTA 6200) up to $1273 \mathrm{~K}$ at a heating rate of $1 \mathrm{~K} \mathrm{~min}^{-1}$ in a mixed flow of oxygen and nitrogen at $200 \mathrm{ml} \mathrm{min}^{-1}$. The cyclic voltammetry measurement was performed within the potential range from 0 to $0.8 \mathrm{~V}$ using a $2.0 M \mathrm{H}_{2} \mathrm{SO}_{4}$ aqueous 


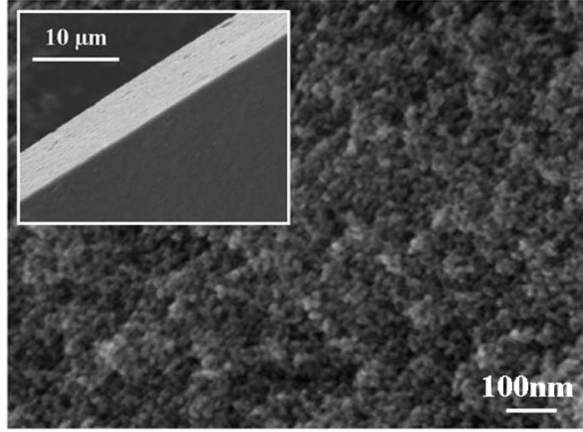

FIG. 1. High- and low-magnification (inset) FE-SEM of CXF.

solution as electrolyte and $\mathrm{Ag} / \mathrm{AgCl}$ as a reference electrode. The potential scan rate was fixed at $10 \mathrm{mV} \mathrm{s}^{-1}$. The directcurrent volume electrical conductivity was measured using a potentiostat/galvanostat (Hokuto Denko, HA-501G) at room temperature.

The high- and low-magnification FE-SEM images of the sample in Fig. 1 show that the sample had relatively uniform pore sizes with a highly disordered pore structure. Mesopores $\sim 10 \mathrm{~nm}$ in width are evident. The CXF was homogeneous with a thickness of several micrometers. It can be fabricated in sizes up to several square centimeters without cracks, as shown by the low-magnification image.

Low-temperature nitrogen adsorption measurement is a common means for evaluating the pore structure of a solid. The adsorption and desorption isotherms of nitrogen on the CXF at $77 \mathrm{~K}$, plotted in Fig. 2, rose steeply below $P / P_{0}$ $=0.02$, and there was a hysteresis loop extending from $P / P_{0}=0.70$ to 0.90 , suggesting the coexistence of micropores and mesopores in the film. There were type IV isotherms and a clear H1 hysteresis loop, suggesting that the mesopores were quite uniform. The micropore and mesopore size distributions (Fig. 2, inset), respectively, determined by the Horváth and Kawazoe method and the Barrett-JoynerHalenda method, were narrow.. The average pore sizes were 0.6 and $9 \mathrm{~nm}$, respectively. This mesopore size is consistent with previously estimated ones from FE-SEM observations. Subtracting pore effect analysis ${ }^{24}$ of the $\mathrm{N}_{2}$ adsorption isotherm showed that the surface area was $915 \mathrm{~m}^{2} \mathrm{~g}^{-1}$, the micropore volume was $0.37 \mathrm{~cm}^{3} \mathrm{~g}^{-1}$, and the mesopore volume was $0.73 \mathrm{~cm}^{3} \mathrm{~g}^{-1}$. This high porosity and the bimodal pore size distribution are distinct advantages for carbon film in terms of capacitance storage because the nanopores (we refer nanopores to micropores and mesopores for convenience ${ }^{25}$ )

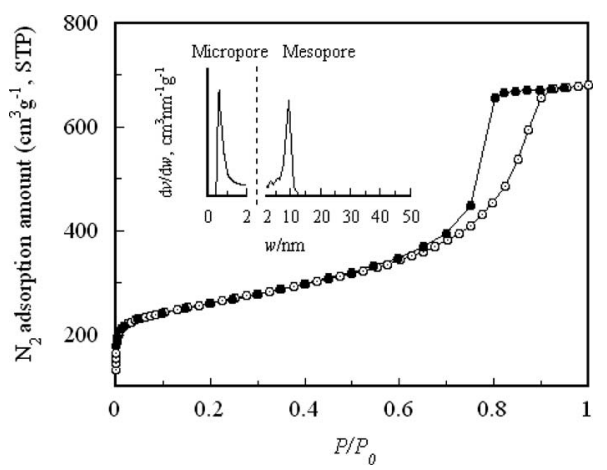

FIG. 2. Nitrogen adsorption $(\bigcirc) /$ desorption $(\bullet)$ isotherms at $77 \mathrm{~K}$ on CXF. Insets show the micropore and mesopore size distributions.

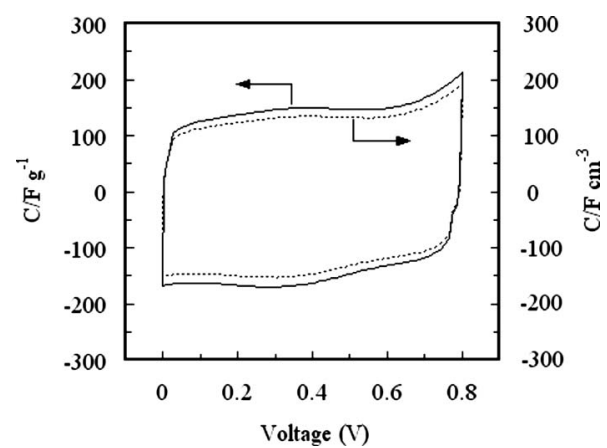

FIG. 3. Cyclic voltammetry graphs of CXF in $2.0 M \mathrm{H}_{2} \mathrm{SO}_{4}$ solution at scan rate of $10 \mathrm{mV} \mathrm{s}^{-1}$.

ensure high-capacity storage, and the interconnected mesopore channels provide fast mass transfer.

The electrochemical behavior of the CXF was characterized by means of the electrical conductivity and cyclic voltammetry measurements. The CXF had a direct-current volume electrical conductivity of $3.5 \times 10^{3} \mathrm{~S} \mathrm{~m}^{-1}$ at room temperature. The cyclic voltammogram of CXF in $2 M$ $\mathrm{H}_{2} \mathrm{SO}_{4(\mathrm{aq})}$ electrolyte solution at a scan rate of $10 \mathrm{mV} \mathrm{s}^{-1}$ was very close to an ideal rectangular shape (Fig. 3), suggesting that energy is retrievable in the discharge over the same potential range as that required to store the energy on charging. The CXF showed a rapid current response on voltage reversal at each end potential. Its appearance density was $0.91 \mathrm{~g} \mathrm{~cm}^{-3}$, much higher than that of ordinary activated carbons. It is noteworthy that the CXF had both a high massspecific capacitance and a volume-specific capacitanceboth of which are required for practical application. Carbon xerogels can be activated with gases such as air, steam, and $\mathrm{CO}_{2}$ to greatly increase the surface area and to modify their surface. ${ }^{23,24,26}$ This means that the capacitance characteristics of CXF can be further improved, which is a future research topic.

The CXF was further characterized by Raman spectroscopy and TGA to investigate its chemical structure. The Raman spectrum [Fig. 4(a)] had two distinct peaks, at 1350 and $1580 \mathrm{~cm}^{-1}$ shifts, which were, respectively, assigned to disordered and ordered carbon phases. From the Raman spectrum, the in-plane microcrystallite size was determined using a method reported elsewhere ${ }^{19}$ to be $2.4 \mathrm{~nm}$. The TG/ derivative thermalgravimetry (DTG) data showed that the CXF decomposed at $773 \mathrm{~K}$ in a mixed flow of oxygen and nitrogen [Fig. 4(b)]. The Raman and TG analysis revealed that the CXF had a chemical structure remarkably similar to that of carbon aerogels synthesized using the standard $\mathrm{CO}_{2}$ supercritical drying process. ${ }^{19,20,26}$ In short, the film was chemically, thermally, and mechanically stable.
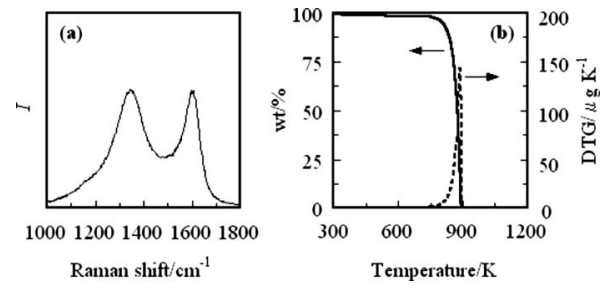

FIG. 4. (a) Raman spectrum of CXF, and (b) TG (solid line), and DTG (dotted line) curves of CXF in a mixed flow of oxygen and nitrogen. 
In conclusion, we showed that uniformly thin carbonbased xerogel film with bimodal micropores and mesopores can be directly fabricated under ambient conditions using a thin reaction space without supercritical drying. The carbon film has a large surface area and well-developed nanoporosity and pore interconnectivity, making it well suited for highcapacitance storage. Its simple and economic preparation should lead to the use of conductive CXF in many electrochemical applications such as gas sensors, biological sensors, and supercapacitors.

This research was supported by CLUSTER (the second stage) of Ministry of Education, Culture, Sports, Science and Technology, Japan, by a Grand-in-Aid for Scientific Research S (Grant No. 15101003) from the Japan government, by a project (Grant No. $18 \lambda$ 06059) from Japan Society for the Promotion of Science (JSPS), and by a 21 COE project of Chiba University.

${ }^{1}$ B. M. Shiflett and C. H. Foley, Science 285, 1902 (1999).

${ }^{2}$ J. Pang, X. Li, D. Wang, Z. Wu, T. V. John, Z. Yang, and Y. F. Lu, Adv. Mater. (Weinheim, Ger.) 16, 884 (2004).

${ }^{3}$ J. B. Hinds, N. Chopra, T. Rantell, R. Andrews, V. Gavalas, and G. L. Bachas, Science 303, 62 (2004).

${ }^{4}$ C. Schmitt, H. Pröbstle, and J. Fricke, J. Non-Cryst. Solids 285, 277 (2001).

${ }^{5}$ C. Liang, S. Dai, and G. Guiochon, Anal. Chem. 75, 4904 (2003).

${ }^{6}$ J. Wang and Q. Chen, Anal. Chem. 66, 1988 (1994).

${ }^{7}$ A. L. Dye and C. J. Trier, J. Microsc. 187, 134 (1997).

${ }^{8}$ G. Y. Gogotsi and M. Yoshimura, Nature (London) 367, 628 (1994).
${ }^{9}$ H. K. Kwok and K. S. W. Chiu, Carbon 41, 673 (2003).

${ }^{10}$ A. Singh, J. Jayaram, M. Madou, and S. Akbar, J. Electrochem. Soc. 149, E78 (2002).

${ }^{11}$ P. K. Gierszal and M. Jaroniec, J. Am. Chem. Soc. 128, 10026 (2006).

${ }^{12}$ H. M. Lu and Y. Zhang, Adv. Mater. (Weinheim, Ger.) 18, 3094 (2006).

${ }^{13}$ M. Choi and R. Ryoo, Nat. Mater. 2, 473 (2003).

${ }^{14}$ A. A. Zakhidov, H. R. Baughman, Z. Iqbal, C. X. Cui, I. Khayrullin, O. S. Nantas, I. Marti, and V. G. Ralchenko, Science 282, 897 (1998).

${ }^{15}$ C. Liang, K. Hong, A. G. Guiochon, J. W. Mays, and S. Dai, Angew. Chem., Int. Ed. 43, 5785 (2004).

${ }^{16}$ J. Pang, Q. Hu, Z. Wu, E. J. Hampsey, J. He, and Y. Lu, Microporous Mesoporous Mater. 97, 472 (2006).

${ }^{17}$ B. H. Han, W. Zhou, and A. Sayari, J. Am. Chem. Soc. 125, 3444 (2003)

${ }^{18}$ S. S. Kistler, Nature (London) 127, 741 (1931).

${ }^{19}$ R. W. Pekala and C. T. Alviso, MRS Symposia Proceedings No. 270 (Materials Research Society, Pittsburgh, 1992), p. 3.

${ }^{20}$ R. W. Pekala, J. Mater. Sci. 24, 3221 (1989); X. Lu, M. C. ArduiniSchuster, J. Kuhn, O. Nilsson, J. Fricke, and R. W. Pekala, Science 255, 971 (1992).

${ }^{21}$ M. S. Dresselhaus and I. L. Thomas, Nature (London) 414, 332 (2001); M. S. Dresselhaus and G. Dresselhaus, J. Electroceram. 1, 273 (1997).

${ }^{22}$ W. Li, G. Reichenauer, and J. Fricke, Carbon 40, 2955 (2002).

${ }^{23}$ S. A. Al-Muhtaseb and J. A. Ritter, Adv. Mater. (Weinheim, Ger.) 15, 101 (2003).

${ }^{24}$ K. Kaneko, C. Ishii, H. Kanoh, Y. Hanzawa, N. Setoyama, and T. Suzuki, Adv. Colloid Interface Sci. 76-77, 295 (1998); S. J. Gregg and K. S. W. Sing, Adsorption, Surface Area and Porosity (Academic, London, 1982).

${ }^{25}$ K. S. W. Sing, D. H. Everett, R. A. W. Haul, L. Moscou, R. A. Pierotti, J. Rouquerol, and T. Siemienjewska, IUPAC Manual of Symbols and Terminology Appendix 2, Pt. 1, Colloid and Surface Chemistry, Pure Appl. Chem. 31, 578 (1972).

${ }^{26}$ Y. Tao, H. Kanoh, L. Abrams, and K. Kaneko, Chem. Rev. (Washington, D.C.) 106, 896 (2006); Y. Tao, H. Kanoh, and K. Kaneko, J. Am. Chem. Soc. 125, 6044 (2003). 